\title{
Quantitative proteomic characterization of microvesicles/exosomes from the cerebrospinal fluid of patients with acute bilirubin encephalopathy
}

\author{
NING TAN ${ }^{1,2^{*}}$, SHUIWANG HU ${ }^{3 *}$, ZHEN HU $^{4}$, ZHOULI WU ${ }^{2}$ and BIN WANG ${ }^{1}$ \\ ${ }^{1}$ Department of Pediatrics, Zhujiang Hospital, The Second School of Clinical Medicine, Southern Medical University, \\ Guangzhou, Guangdong 510280; ${ }^{2}$ Department of Neonatology, Affiliated The First People's Hospital of Chenzhou, \\ Southern Medical University, University of South China, Chenzhou, Hunan 423000; ${ }^{3}$ Guangdong Provincial \\ Key Laboratory of Proteomics, Department of Pathophysiology, Southern Medical University, Guangzhou, \\ Guangdong 510515; ${ }^{4}$ National and Local Joint Engineering Laboratory for High-through Molecular Diagnosis Technology, \\ Translational Medicine Institute, Collaborative Research Center for Post-doctoral Mobile Stations of \\ Central South University, Affiliated The First People's Hospital of Chenzhou, Southern Medical University, \\ University of South China, Chenzhou, Hunan 423000, P.R. China
}

Received December 3, 2019; Accepted May 6, 2020

DOI: $10.3892 / \mathrm{mmr} .2020 .11194$

\begin{abstract}
Severe hyperbilirubinemia causes neurotoxicity and may lead to acute bilirubin encephalopathy (ABE) during the critical period of central nervous system development. The aim of the present study was to identify differentially expressed proteins (DEPs) in microvesicles/exosomes (MV/E) isolated from the cerebrospinal fluid (CSF) of patients with ABE. Co-precipitation was used to isolate the MV/E from the CSF of patients with $\mathrm{ABE}$ and age-matched controls. Isobaric tagging for relative and absolute quantification-based proteomic technology combined with liquid chromatography/tandem mass spectrometry was used to identify DEPs in the MV/E. Bioinformatics analysis was subsequently performed to
\end{abstract}

Correspondence to: Professor Bin Wang, Department of Pediatrics, Zhujiang Hospital, The Second School of Clinical Medicine, Southern Medical University, 253 Industrial Avenue, Haizhu, Guangzhou, Guangdong 510280, P.R. China

E-mail: wangbin6336@163.com

${ }^{*}$ Contributed equally

Abbreviations: ABE, acute bilirubin encephalopathy; BIND, bilirubin-induced neurological dysfunction; CSF, cerebrospinal fluid; DEPs, differentially expressed proteins; GO, Gene Ontology; iTRAQ, isobaric tagging for relative and absolute quantification; KEGG, Kyoto Encyclopedia of Genes and Genomes; MV/E, microvesicles/exosomes; MS/MS, tandem mass spectrometry; NTA, nanoparticle tracking analysis; UPLC, ultimate high-performance liquid chromatography

Key words: proteomics, exosomes, microvesicles, acute bilirubin encephalopathy, cerebrospinal fluid investigate Gene Ontology functional annotation and Kyoto Encyclopedia of Genes and Genomes enriched signaling pathways of these DEPs. A total of four proteins were selected for further validation via western blotting. A total of 291 dysregulated proteins were identified by comparing the patients with $\mathrm{ABE}$ with the controls. Bioinformatics analysis indicated the involvement of immune-inflammation-associated cellular processes and signaling pathways in the pathophysiology of $\mathrm{ABE}$. In conclusion, the present study identified the proteomic profile of $\mathrm{MV} / \mathrm{E}$ isolated from the CSF of patients with ABE. These results may provide an improved understanding of the pathogenesis of ABE and may help to identify early diagnostic biomarkers and therapeutic targets.

\section{Introduction}

Neonatal hyperbilirubinemia primarily occurs in term newborns and in $>84 \%$ of late preterm newborns (1). Extreme neonatal hyperbilirubinemia may lead to the accumulation of bilirubin in the brain stem nuclei, cerebellum and basal ganglia, and subsequently cause acute bilirubin encephalopathy (ABE) (2). ABE is a serious disease that can cause death or a lifelong neurodevelopmental disorder, known as chronic bilirubin encephalopathy or kernicterus (3). Although the incidence of $\mathrm{ABE}$ has declined, the reported incidence rate in developed countries in 2009-2018 ranged from 0.4-2.7 cases per 100,000 births $(4,5)$. Moreover, the reported incidence rates of $\mathrm{ABE}$ in Asia, the Middle East and Africa have been reported to be notably higher than in Western developed countries (6-8).

ABE is a clinical bilirubin-induced neurological dysfunction (BIND) characterized by poor feeding, lethargy, hypotonia and opisthotonus $(9,10)$. The neurotoxicity is due to the diffusion of unconjugated bilirubin (UCB) into brain cells after traversing the blood-brain barrier (10). High concentrations of 
UCB exert neurotoxic effects by inducing a number of cellular and molecular events (e.g., neuronal excitotoxicity, mitochondrial energy failure, activation of apoptotic or necrosis pathways) (11). The in vitro exposure of neurons to UCB has been identified to induce cellular macroscopic changes, such as decreased dendritic and axonal arborization, neurite extension and ramification, and cell proliferation (12). Non-neuronal cells, such as astrocytes, microglia and oligodendrocytes, have also demonstrated sensitivity to UCB, which triggered the secretion of inflammatory mediators, including tumor necrosis factor (TNF) and interleukin (IL)-1 $(13,14)$, upregulated the activity of matrix-metalloproteinases 2 and 9 (15) and increased caspase 3-mediated apoptosis (16). In addition, cultured vascular endothelial cells of the blood-brain barrier and the blood-cerebrospinal fluid (CSF) barrier were observed to exhibit upregulated P-glycoprotein/ABCB1 and downregulated multidrug resistance-associated protein $1 / \mathrm{ABC}$, $\mathrm{C} 1$ expression levels, respectively, upon the exposure to high concentrations of bilirubin (17). Moreover, bilirubin-induced endoplasmic reticulum stress was previously demonstrated to contribute to inflammatory processes and apoptosis in neuronal cells, which indicated the involvement of endoplasmic reticulum stress in UCB-induced neurotoxicity (18).

However, despite numerous cell and animal experiments, the basic mechanisms of ABE are not fully understood. Over previous years, there has been an increasing interest in extracellular microvesicles/exosomes (MV/E), which are released from a number of cells, including glial cells, neurons and astrocytes in the brain (19). MV/E are membrane-bound nanovesicles that serve as important mediators of intercellular communication by transporting molecular signals, including proteins, mRNA and microRNAs, between cells $(20,21)$. High-throughput proteomics technology has been used to identify underlying mechanisms associated with the initiation and development of numerous types of cerebral disease (22-24). However, to the best of our knowledge, few studies have investigated the molecular mechanism of bilirubin-induced neurotoxicity based on proteomics techniques or extracellular MV/E $(12,25,26)$. Therefore, focusing on the proteomics of $\mathrm{MV} / \mathrm{E}$ may elucidate the mechanisms of bilirubin-induced neurological neurotoxicity. The aim of the present study was to obtain protein profiles of extracellular vesicles from the CSF of patients with ABE. These results may help determine the pathogenesis of $\mathrm{ABE}$ and provide novel perspectives for the early diagnosis and treatment of ABE.

\section{Materials and methods}

Participant characteristics and CSF collection. The study protocol was approved by the Ethics Committee of Affiliated First People's Hospital of Chenzhou, Southern Medical University, University of South China (Chenzhou, China). Written informed consent was obtained from parents/caregivers of all subjects prior to the start of the study. All experimental procedures were performed in accordance with the Declaration of Helsinki (27).

All subjects in the present study were full-term newborns $(n=30)$ recruited between January 2017 and November 2019 from the Department of Neonatology of the Affiliated First People's Hospital of Chenzhou, Southern
Medical University. Patient characteristics are presented in Table I. Patients with ABE were diagnosed according to the clinical BIND score; BIND scores of 1-3, 4-6 and 7-9 are indicative of mild, moderate and severe ABE, respectively (28). The inclusion criteria for patients with ABE in the present study were: Newborns, aged $\leq 14$ days who required exchange transfusion and had clinical BIND scores of $>4(3,28)$. Patients with ABE were divided into moderate $(n=10)$ and severe groups $(n=10)$. The control group $(n=10)$ comprised full-term newborns who required lumbar puncture to exclude sepsis and meningitis, but who were not diagnosed with sepsis or meningitis due to normal CSF and peripheral blood test results. A total of four patients in the control group were diagnosed with pneumonia; six were diagnosed with enteritis. The demographic and clinical characteristics of the subjects are presented in Table I. Newborns with congenital cerebral malformation or secondary brain injury due to other causes (such as hypoglycemic encephalopathy, hypoxic-ischemic encephalopathy, intracranial hemorrhage, epilepsy, sepsis, meningitis or inherited metabolic diseases) were excluded from the present study.

CSF samples were obtained at the time of diagnosis of $\mathrm{ABE}$, while samples from controls were obtained prior to the administration of antibiotics at admission. CSF samples $(2.5 \mathrm{ml})$ were collected via lumbar puncture and centrifuged at $2,000 \mathrm{x} \mathrm{g}$ for $20 \mathrm{~min}$ at $4^{\circ} \mathrm{C}$ and stored at $-80^{\circ} \mathrm{C}$ until analysis.

Isolation of MV/E via co-precipitation. A volume of $1 \mathrm{ml}$ supernatant was pipetted into an Eppendorf tube and mixed with $330 \mu \mathrm{l} \mathrm{Ribo}^{\mathrm{TM}}$ exosome isolation reagent (cat. no. C10120; Guangzhou Ribobio Co., Ltd.). The tube was subsequently placed in a refrigerator at $4^{\circ} \mathrm{C}$ for $30 \mathrm{~min}$, then centrifuged at $15,000 \mathrm{x}$ g for $2 \mathrm{~min}$ at $4^{\circ} \mathrm{C}$. The resultant precipitate was the crude $\mathrm{MV} / \mathrm{E}$-enriched fraction, which was resuspended and further diluted with1 $\mathrm{ml} 1 \mathrm{X}$ PBS to achieve the detectable concentration $\left(10^{6}\right.$ particles $\left./ \mathrm{ml}\right)$ for further analysis.

Nanoparticle tracking analysis (NTA). In order to characterize $\mathrm{MV} / \mathrm{E}$, NTA was performed using the NanoSight NS300 instrument (Malvern Panalytical). The crude $\mathrm{MV} / \mathrm{E}$-enriched fraction were diluted with $1 \mathrm{ml} 1 \mathrm{X}$ PBS to achieve a suitable concentration $\left(10^{6}\right.$ particles $\left./ \mathrm{ml}\right)$, and then injected into the detection chamber (flow rate, $35 \mu \mathrm{l} / \mathrm{second}$; temperature $23.1-23.7^{\circ} \mathrm{C}$ ) equipped with a $405 \mathrm{~nm}$ (purple) laser. The parameters were adjusted to the best condition according to the manufacturer's instructions, and samples were measured three times. Data were analyzed using NTA 3.2 Dev Build 3.2.16 software (Malvern Panalytical) and SOP Standard Measurement. The NTA technology combines a video imaging system and laser light scattering microscopy to obtain the nanoparticle size distribution of samples in liquid suspension (29). Brownian motion of each particle was measured and analyzed individually. A light beam is used to illuminate the particles in the sample. As the particles scatter light and undergo Brownian motion, a scientific CMOS camera recorded the path of each particle to determine the mean velocity and diffusivity. The particle concentration and size distribution were calculated according to a modified Stokes-Einstein relationship (30). 
Table I. Characteristics of the study population.

Patients with acute bilirubin encephalopathy

\begin{tabular}{|c|c|c|c|c|}
\hline \multirow{2}{*}{ Variables } & & \multirow[b]{2}{*}{ Control group } & \multirow[b]{2}{*}{ P-value } \\
\hline & Moderate group & Severe group & & \\
\hline Number & 10 & 10 & 10 & \\
\hline Female/male & $4 / 6$ & $3 / 7$ & $5 / 5$ & \\
\hline Gestational age, weeks & $38.60 \pm 1.40$ & $38.20 \pm 1.70$ & $38.40 \pm 1.34$ & 0.930 \\
\hline Birth weight, $g$ & $3,513.50 \pm 188.18$ & $3,498.30 \pm 135.13$ & $3,505.40 \pm 240.86$ & 0.985 \\
\hline Age at admission, days & $5.70 \pm 0.95$ & $5.50 \pm 1.08$ & $6.40 \pm 1.57$ & 0.248 \\
\hline Peak serum TB levels, $\mu \mathrm{mol} / \mathrm{l}$ & $485.40 \pm 20.30$ & $587.50 \pm 57.50$ & $77.21 \pm 19.70$ & $<0.001$ \\
\hline $\begin{array}{l}\text { Bilirubin-induced neurological } \\
\text { dysfunction score at admission }\end{array}$ & $4.80 \pm 0.91$ & $8.50 \pm 0.71$ & & $<0.001$ \\
\hline \multicolumn{5}{|l|}{ Routine test of cerebrospinal fluid } \\
\hline Number of cells, $10^{6} / 1$ & $7.60 \pm 2.01$ & $7.50 \pm 1.58$ & $6.90 \pm 1.96$ & 0.666 \\
\hline Protein concentration, mg/l & $810.50 \pm 94.96$ & $790.26 \pm 107.76$ & $745.90 \pm 131.77$ & 0.289 \\
\hline \multicolumn{5}{|l|}{ Peripheral blood test } \\
\hline White blood cells, $10^{9} / 1$ & $8.99 \pm 1.03$ & $9.11 \pm 1.16$ & $8.54 \pm 1.44$ & 0.553 \\
\hline C-reactive protein, $\mathrm{mg} / \mathrm{l}$ & $2.41 \pm 1.040$ & $2.46 \pm 1.15$ & $2.52 \pm 0.78$ & 0.970 \\
\hline Procalcitonin, ng/ml & $0.18 \pm 0.09$ & $0.23 \pm 0.12$ & $0.19 \pm 0.15$ & 0.617 \\
\hline \multicolumn{5}{|l|}{ Cause of hyperbilirubinemia } \\
\hline Hemolysis, yes/no & $3 / 7$ & $4 / 6$ & & \\
\hline Idiopathic, yes/no & $1 / 9$ & $1 / 9$ & & \\
\hline $\begin{array}{l}\text { Glucose-6-phosphate 1-dehyrodgenase } \\
\text { deficiency, yes/no }\end{array}$ & $6 / 4$ & $5 / 5$ & & \\
\hline Treatment & $\mathrm{ET}+\mathrm{PT}$ & $\begin{array}{c}\mathrm{ET}+\mathrm{PT}+ \\
\text { intravenous albumin }\end{array}$ & & \\
\hline
\end{tabular}

Bilirubin-induced neurological dysfunction scores of 1-3, 4-6 and 7-9 are indicative of mild, moderate and severe acute bilirubin encephalopathy, respectively (28). Data are presented as the mean \pm SD. TB, total bilirubin; PT, phototherapy; ET, exchange transfusion.

Protein extraction, reduction, alkylation, digestion and isobaric tagging for relative and absolute quantification (iTRAQ)-4 plex labeling. For protein extraction, all pooled $\mathrm{MV} / \mathrm{E}$ samples were removed from ice. Each sample was added to x10 the volume of protein lysis buffer (8 M urea, $1 \%$ SDS, $1 \mathrm{X}$ protease inhibitor cocktail) with an ultrasonic cell disruptor $(25 \mathrm{kHz})$ for $2 \mathrm{~min}$ in an ice bath and then allowed to react for $30 \mathrm{~min}$ on ice. Subsequently, precooled $100 \%$ acetone (acetone:sample ratio, 5:1) was added and incubated at $-20^{\circ} \mathrm{C}$ overnight to precipitate the protein. The sample was centrifuged for $30 \mathrm{~min}$ at $12,000 \mathrm{x}$ g at $4^{\circ} \mathrm{C}$, and the precipitate was cleaned using $90 \%$ acetone and centrifuged again for $30 \mathrm{~min}$ at $12,000 \mathrm{x}$ g at $4^{\circ} \mathrm{C}$. Then, the supernatant was discarded, and the precipitate was fully dissolved in protein lysis buffer and centrifuged for $30 \mathrm{~min}$ at $12,000 \mathrm{xg}$ at $4^{\circ} \mathrm{C}$.

Proteins were quantified via $\mathrm{BCA}$ assay. For protein reduction and alkylation, protein lysis buffer was added to $50 \mu \mathrm{g}$ protein samples to a volume of $150 \mu \mathrm{l}$. Then, $10 \mathrm{mM}$ Bond-Breaker ${ }^{\mathrm{TM}}$ Tris (2-carboxyethyl) phosphine solution (Thermo Fisher Scientific, Inc.) was added to the sample and incubated for $60 \mathrm{~min}$ at $37^{\circ} \mathrm{C}$. Following the incubation, 10 $\mu$ solution ( $40 \mathrm{mM}$ iodoacetamide in $40 \mathrm{mM} \mathrm{NH} \mathrm{HCO}_{3}$ ) was added to the sample and incubated for $40 \mathrm{~min}$ at $37^{\circ} \mathrm{C}$ in the dark. Precooled $100 \%$ acetone (acetone: sample volume ratio,
6:1) was added to each tube for precipitation at $-20^{\circ} \mathrm{C}$ for $4 \mathrm{~h}$. Then, the sample was centrifuged at $10,000 \mathrm{x}$ g for $20 \mathrm{~min}$ at $4^{\circ} \mathrm{C}$ and the precipitate was completely dissolved in $100 \mu \mathrm{l}$ triethylammonium bicarbonate (TEAB; $100 \mathrm{mM}$ ).

For subsequent protein tryptic digestion, $2 \mu 1$ trypsin $(0.5 \mu \mathrm{g} / \mathrm{ml})$ was added to each sample. Each sample was vortexed briefly, covered with parafilm to prevent evaporation and incubated overnight at $37^{\circ} \mathrm{C}$. Subsequently, samples were desalted using a Sep-Pak C18 cartridge (particle size, 55-105 $\mu \mathrm{m}$ ) (Waters Corporation) according to the manufacturer's instructions, and then vacuum dried. For iTRAQ-4 plex labeling, $100 \mu \mathrm{g}$ digested peptides were dissolved in $0.5 \mathrm{M}$ TEAB and labeled with the iTRAQ reagents 4-plex kit (cat. no. 43374321; Shanghai AB SCIEX Analytical Instrument Trading Co.), according to the manufacturer's protocol. iTRAQ reagents 114,115 and 116 from the iTRAQ reagents 4-plex kit were used to label digested peptides of the control, moderate and severe groups, respectively. After reacting for $2 \mathrm{~h}$ at room temperature, $40 \mu \mathrm{g}$ labeled peptides in each group were mixed together in a tube and vacuum concentrated for high-performance liquid chromatography analysis (HPLC).

Ultimate HPLC (UPLC). In order to decrease sample complexity, first-dimensional separation of the iTRAQ-labeled 
mixed peptides was performed using the ACQUITY UPLC system (Waters Corporation). The peptide mixture $(120 \mu \mathrm{g})$ was reconstituted withsolvent A $(20 \mathrm{mM}$ ammonium formate; $2 \%$ acetonitrile; $\mathrm{pH} 10.0$ ) to $25 \mu \mathrm{l}$ and loaded onto the ACQUITY UPLC BEH C18 column (grain size, $1.7 \mu \mathrm{m}$; $2.1 \times 150.0 \mathrm{~mm}$; temperature, $37^{\circ} \mathrm{C}$; Waters Corporation) through an autosampler (temperature, $10^{\circ} \mathrm{C}$ ). The peptides were separated at $200 \mu \mathrm{l} / \mathrm{min}$ for $37 \mathrm{~min}$ via a linear gradient, which was established by mixing solvents A and B $(20 \mathrm{mM}$ ammonium formate; $80 \%$ acetonitrile; $\mathrm{pH} 10.0)$ as follows: 0-5 min, 0.0-3.8\% solvent $\mathrm{B}$ in solvent $\mathrm{A}$; 6-16 min, 4-43\% solvent B in solvent A; $17-37$ min, $100 \%$ solvent B in solvent A. The ultraviolet detection wavelength was set at $214 \mathrm{~nm}$. A total of 5 fractions were collected based on peak area, then vacuum dried and stored at $-80^{\circ} \mathrm{C}$ for further liquid chromatography with tandem mass spectrometry (LC-MS/MS) analysis.

Reverse-phase LC-MS/MS. Second-dimensional reverse phase LC-MS/MS was performed at room temperature to separate and identify the digested samples ( $1 \mu \mathrm{g}$ /fraction). The chromatographic separation was performed using the EASY-nLC 1200 system on a C18 column $(75 \mu \mathrm{m}$ x $25 \mathrm{~cm}$; Thermo Fisher Scientific, Inc.). The mobile phase contained solvents A (2\% acetonitrile with $0.1 \%$ formic acid) and B (80\% acetonitrile with $0.1 \%$ formic acid). The samples were resuspended in $40 \mu \mathrm{l}$ solvent A to a concentration of $0.5 \mu \mathrm{g} / \mu \mathrm{l}$ and were fractionated sequentially. The total fractionation time was $120 \mathrm{~min}$ at a flow rate of $300 \mathrm{nl} / \mathrm{min}$ via a linear gradient profile, which was established by mixing solvent $\mathrm{A}$ and solvent $\mathrm{B}$ as follows: 0-63 min, 0-23\% solvent $\mathrm{B}$ in solvent A; 64-88 min, $23-48 \%$ solvent $B$ in solvent $A ; 89-120$ min, $100 \%$ solvent $B$ in solvent $\mathrm{A}$.

A Q-Exactive hybrid quadrupole-Orbitrap mass spectrometer (Thermo Fisher Scientific, Inc.) equipped with an EASY-nLC ${ }^{\text {TM }} 1200$ nanoflow LC system (Thermo Fisher Scientific, Inc.) was used for qualitative analysis using electrospray ionization in the positive mode. The conditions for MS were: Source temperature, $350^{\circ} \mathrm{C}$; spray voltage, $-3 \mathrm{kv}$; nebulizer gas pressure, $35 \mathrm{psi}$; and nebulizer nitrogen flow rate, $10 \mathrm{l} / \mathrm{min}$. The data-dependent MS acquisition mode was used to select the top 20 most abundant ions for subsequent analysis. The mass spectrum scanning range $(\mathrm{m} / \mathrm{z})$ was set at $350-1,300 \mathrm{~m} / \mathrm{z}$ and the mass spectrum resolution was 70,000 . For MS/MS, the top 20 intense precursor ions were sequentially subjected to higher energy collision dissociation. The fragment ions were detected at a mass resolution of 17,500 . Dynamic exclusion was set for $18 \mathrm{sec}$. Thermo Xcalibur ${ }^{\mathrm{TM}} 4.0$ (Thermo Fisher Scientific, Inc.) software was used for data acquisition. A total of three biological repeats was performed to minimize the experimental variation.

Data analysis and bioinformatics. The raw data was sifted using Proteome Discoverer ${ }^{\mathrm{TM}} 2.1$ software (Thermo Fisher Scientific, Inc.) and was searched against the UniProt Homo sapiens database (uniprot-proteome-UP000005640-Homo sapiens-20180626-73045s.fasta) using Mascot software (version 2.3.0; Matrix Science, Inc.). The search parameters were as follows: i) Dynamic modification: Oxidation (M), acetyl (Protein N-Terminus), iTRAQ4plex (Y); ii) static modification: iTRAQ4plex (K), iTRAQ4plex (N-Terminus), carbamidomethyl (C); iii) enzyme, trypsin; iv) maximum missed cleavage sites, 2; v) precursor mass tolerance, 20 ppm; vi) fragment mass tolerance, $0.05 \mathrm{Da}$; and vii) requirements for protein identification: Two peptides or $\geq 1$ unique peptide to match. The cut-off values for differentially expressed proteins (DEPs) were set at fold change $>1.2$ or $<0.83$ and $\mathrm{P}<0.05$. All P-values were corrected for multiple hypotheses testing by controlling the false discovery rate (FDR). $\mathrm{P}<0.05$ and FDR $<0.05$ were considered to indicate a statistically significant difference.

Gene Ontology (GO) consortium (geneontology.org/) was used for functional term annotation and enrichment analysis using the UniProt accession numbers of the identified DEPs. The Kyoto Encyclopedia of Genes and Genomes (KEGG) database (kegg.jp/) was used for signaling pathway enrichment analysis. In addition, a protein-protein interaction (PPI) network of the DEPs was constructed using the Search Tool for the Retrieval of Interacting Genes/Proteins (STRING) software (version 10.5; string-db.org/) (confidence score $\geq 0.4$ ). Fisher's exact values and Q-values (corrected using FDR) $<0.05$ were considered significant for the GO functional term and KEGG signaling pathway enrichment analysis.

Western blotting validation. A total of four DEPs [S100A9, S100A7, lactoferrin (LTF) and $\alpha$ defensin 1 (DEFA1)] were selected for further validation. The selection criteria for validation were: i) Fold change $>1.5$ or $<0.67$ and $\mathrm{P}<0.05$; ii) DEPs were upregulated or downregulated in both the ABE and control groups; iii) results of the bioinformatics analysis (GO functional annotation and KEGG signaling pathways analysis of DEPs); iv) potential association with ABE pathogenesis, based on existing knowledge; and v) not previously studied in patients with ABE.

Proteins from harvested MV/E of CSF were extracted using protein extraction buffer [50 Tris- $\mathrm{HCl}(\mathrm{pH}, 6.8), 100$ mM DTT, 2\% SDS, $0.1 \%$ bromophenol blue, $10 \%$ glycerol] and quantified via BCA assay. Proteins samples were separated by $12 \%$ SDS-PAGE at room temperature using $30 \mathrm{~mA}$ constant current electrophoresis and $50 \mu \mathrm{g}$ protein was loaded per lane. The separated proteins were subsequently transferred onto PVDF membranes and blocked with $5 \%$ non-fat milk in TBST $(0.1 \%$ Tween-20) for $60 \mathrm{~min}$ at room temperature. The membranes were washed three times with TBST for $5 \mathrm{~min}$ and incubated with primary antibodies at $4^{\circ} \mathrm{C}$ overnight. Following the primary antibody incubation, the membranes were washed three times with TBST for $5 \mathrm{~min}$ and incubated for $60 \mathrm{~min}$ at room temperature with a horseradish peroxidase-conjugated secondary antibody $(1: 1,000)$ as follows: Goat anti-mouse (cat. no. SC-3697; Santa Cruz Biotechnology, Inc.), goat anti-rabbit (cat. no. G-21234; Thermo Fisher Scientific, Inc.), rabbit anti-goat (cat. no. 81-1620; Thermo Fisher Scientific, Inc. The chromogenic reaction was developed using a chemiluminescent substrates kit (Amresco, LLC). Images were visualized using a KodakImage Station 4000R digital imaging system (Kodak). The Quantity One software (version 4.6.7; Bio-Rad Laboratories, Inc) was used for densitometric analysis. The primary antibodies (all 1:1,000) were as follows: Monoclonal anti-CD9 and anti-LTF (cat. nos. sc-59140 and sc-53498, respectively; both Santa Cruz Biotechnology, Inc.), polyclonal anti-DEFA1 (cat. no. PA5-19228; Thermo Fisher Scientific, 


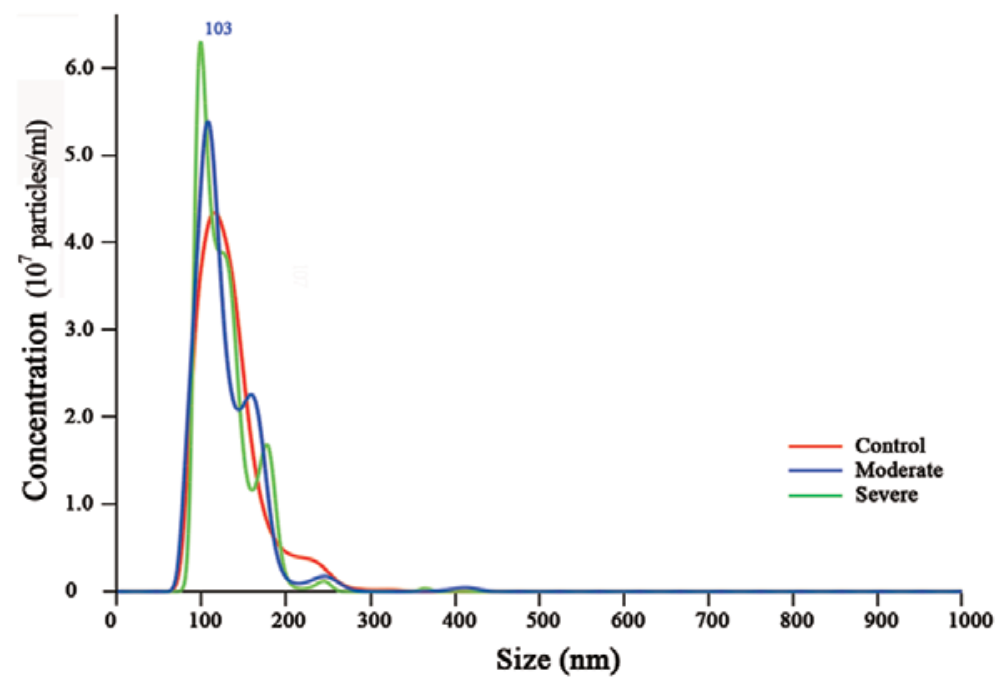

Figure 1. MV/E particle size distribution and scattering intensity analysis using nanoparticle tracking analysis. Concentration particle size curve: Representative particle size distribution of the MV/E samples obtained from patients with acute bilirubin encephalopathy and controls. MV/E, microvesicle/exosome.

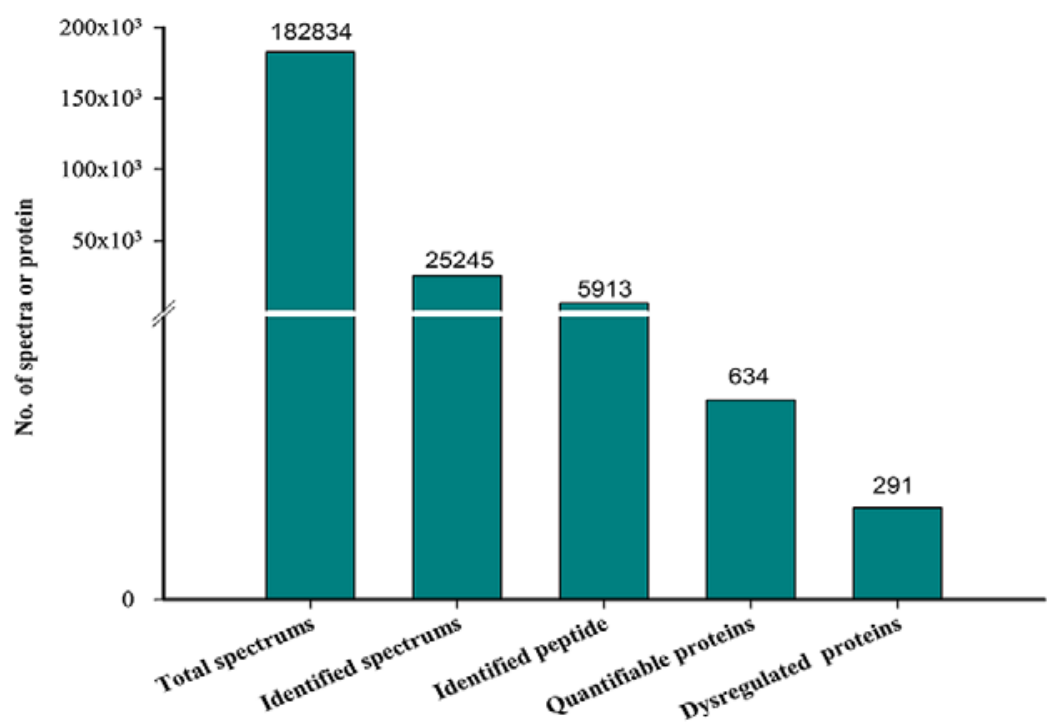

Figure 2. The numbers of spectrums, peptides and proteins identified in the microvesicles/exosomes of controls and patients with acute bilirubin encephalopathy using tandem mass spectrometry.

Inc.) and polyclonal anti-S100A7 and anti-S100A9 (cat. nos. PA5-75689 and PA1-46489, respectively; both Thermo Fisher Scientific, Inc.).

Statistical analysis. Statistical analysis was performed using the SPSS statistical package (version 20.0; IBM Corp.). Continuous variables are presented as the mean $\pm \mathrm{SD}$ of three experimental repeats. One-way ANOVA and Bonferroni's post hoc test were performed to evaluate the statistical differences between multiple group comparisons. $\mathrm{P}<0.05$ was considered to indicate a statistically significant difference.

\section{Results}

NTA of $M V / E$ from patients with $A B E$ and controls. Representative particle concentration distribution and size scattering intensity analysis of MV/E samples is presented in Fig. 1. The particle size of MV/E from patients with $\mathrm{ABE}$ and controls ranged from $75-200 \mathrm{~nm}$ in diameter and the peak concentration of the particle of $\mathrm{MV} / \mathrm{E}$ from patients with $\mathrm{ABE}$ and controls was at $103 \mathrm{~nm}$ in diameter. The three curves overlapped, which indicated that the three groups of samples were homogeneous and that there were few impurities, which suggested the successful isolation of $\mathrm{MV} / \mathrm{E}$ from the CSF.

Qualitative results of dysregulated proteins. A total of 182,834 MS/MS spectra were obtained via iTRAQ-based proteomics and 25,245 peptide spectrum matches (PSMs) were matched to 5,913 peptides. A total of 634 proteins were identified and 291 dysregulated proteins were selected for further study (Fig. 2; Table SI). Of the 291 proteins, 186 DEPs (75 upregulated and 111 downregulated proteins) were identified between the severe and moderate groups (Table SII). A total of 119 DEPs (37 upregulated and 82 downregulated proteins) were identi- 
A

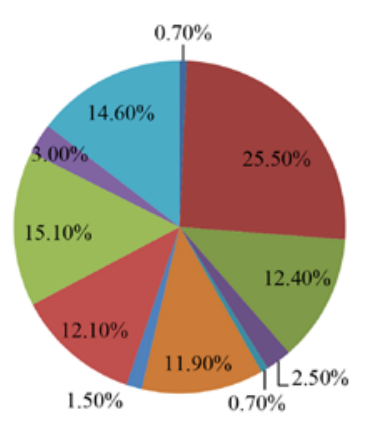

- Cellular component organization or biogenesis (GO:0071840)

- Cellular process (GO:0009987)

= Localization (GO:0051179)

- Biological adhesion (GO:0022610)

= Reproduction (GO:0000003)

= Biological regulation (GO:0065007)

= Developmental process (GO:0032502)

= Response to stimulus (GO:0050896)

$=$ Metabolic process (GO:0008152)

= Multicellular organismal process (GO:0032501)

= Immune system process (GO:0002376)

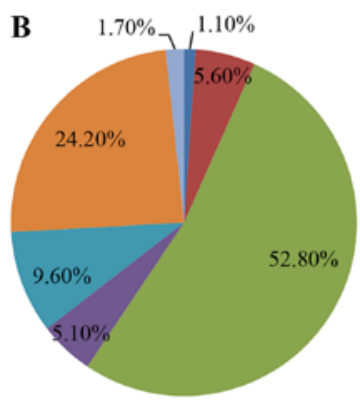

= Transcription regulator activity (GO:01401 10)

- Molecular transducer activity (GO:0060089)

$=$ Binding (GO:0005488)

- Structural molecule activity (GO:0005198)

- Molecular function regulator (GO:0098772)

= Catalytic activity (GO:0003824)

= Transporter activity (GO:0005215)

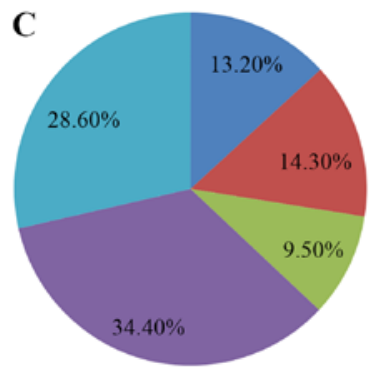

$=$ Membrane (GO:0016020)

= Protein-containing complex (GO:0032991)

= Organelle (GO:0043226)

= Extracellular region (GO:0005576)

$=$ Cell (GO:0005623)

Figure 3. Gene Ontology annotation analysis of differentially expressed proteins in the microvesicles/exosomes of patients with acute bilirubin encephalopathy. (A) Biological process. (B) Molecular function. (C) Cellular component.

fied between the severe and control groups (Table SIII) and 194 DEPs (92 up- and 102 downregulated proteins) were identified between the moderate and control groups (Table SIV). Certain DEPs [serum amyloid A-1 protein (SAA1), amyloid- $\beta$ precursor protein (APP), immunoglobulin-like domains (immunoglobulin heavy constant $\gamma 4$ and immunoglobulin heavy variable 2-5), complement components (C4B and C5), S100A9, S100A7, DEFA1 and LTF] were identified between the $\mathrm{ABE}$ and control groups (Table SI).

GO annotation and functional term enrichment analysis of DEPs. GO annotation of all DEPs was categorized according to biological process (BP), molecular function (MF) and cellular components (CC). The majority of DEPs were associated with 'cellular process', 'immune system process' and 'metabolic process' (Fig. 3A) and the identified MFs indicated that the DEPs were primarily involved in 'binding' and 'catalytic activity' (Fig. 3B). In addition, the DEPs were revealed to be primarily located in the 'cell' and 'extracellular region' (Fig. 3C).

GO enrichment analysis revealed that the majority of the DEPs were primarily enriched in 'immune system process', 'response to stimulus' and 'biological regulation' in the BPs. In
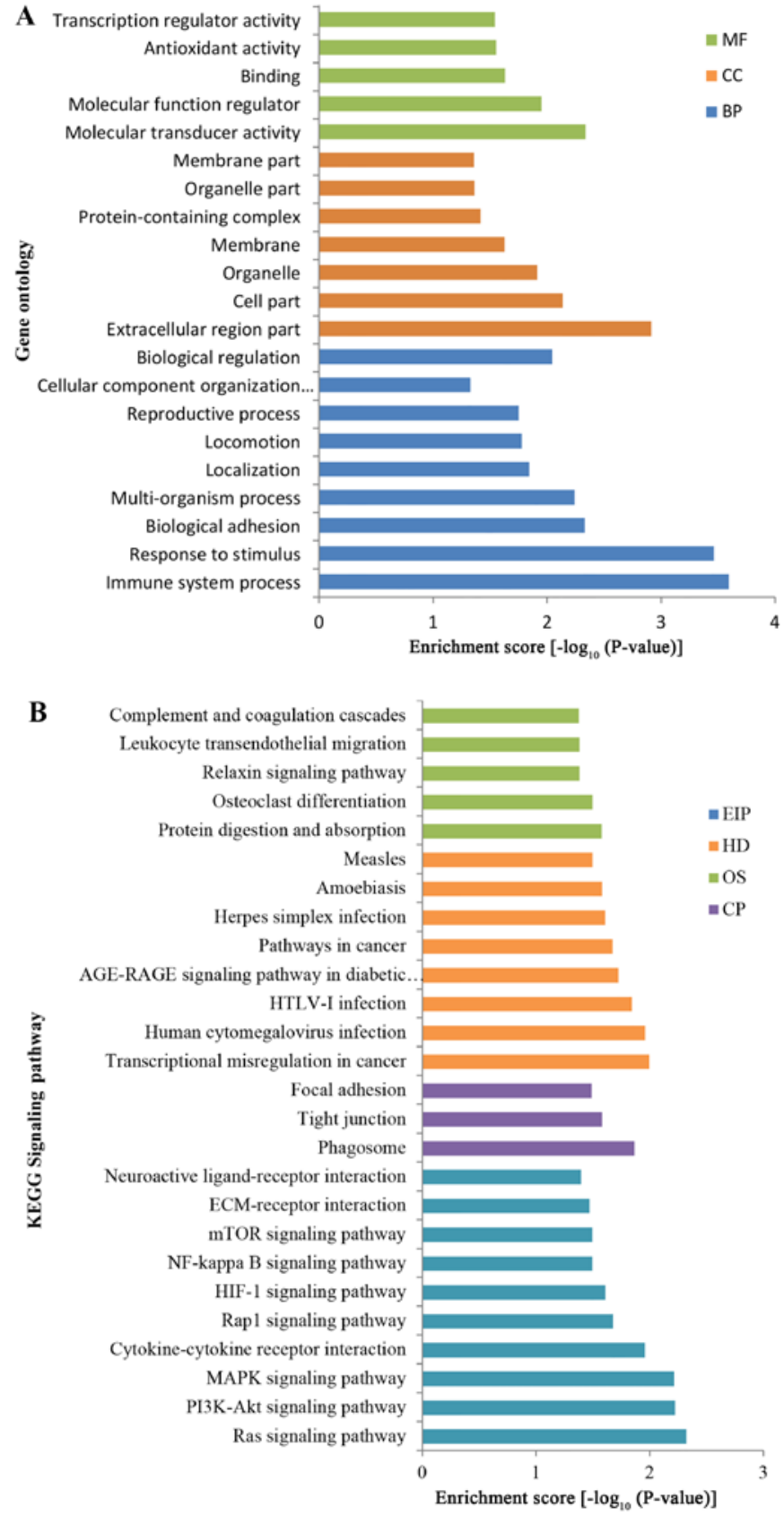

Figure 4. Enrichment analysis of DEPs. (A) Gene Ontology functional term enrichment analysis of DEPs in patients with ABE (B) KEGG signaling pathway enrichment analysis of DEPs in patients with ABE. DEP, differentially expressed protein; ABE, acute bilirubin encephalopathy; KEGG, Kyoto Encyclopedia of Genes and Genomes CC cellular component; MF, molecular function; BP, biological process; $\mathrm{CP}$, cellular processes; HD, human diseases; EIP, environmental information processing; OS, organismal systems.

addition, the MFs of the DEPs were primarily associated with 'molecular transducer activity', 'molecular function regulator' and 'transcription regulator activity', whilst the DEPs were identified to be primarily located in 'extracellular region part' and 'cell part' (Fig. 4A).

KEGG signaling pathway enrichment analysis. KEGG signaling pathway enrichment analysis was performed to profile the functional differences of the proteomes of $\mathrm{MV} / \mathrm{E}$ isolated from the CSF of patients with ABE and the controls. Significantly enriched signaling pathways of patients with 


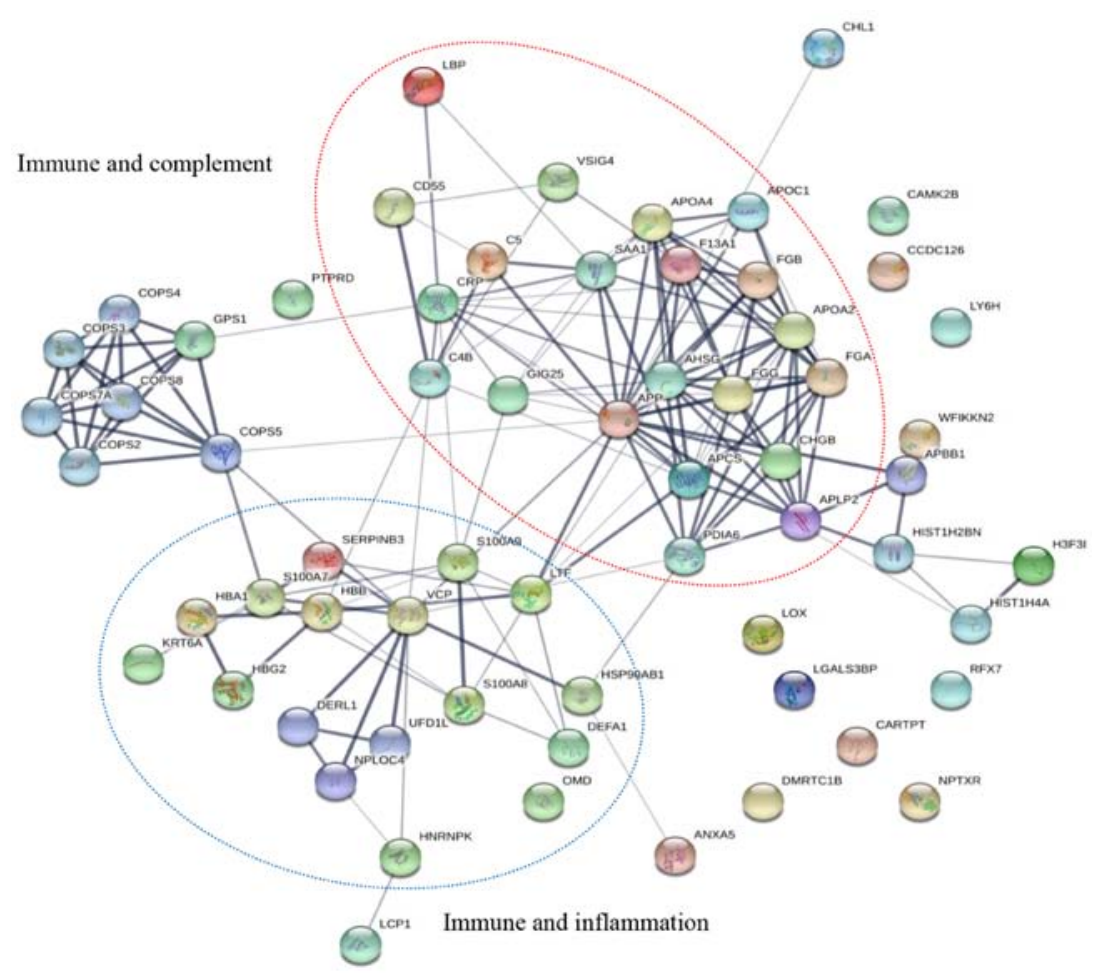

Figure 5. Protein-protein interaction analysis of differentially expressed proteins in patients with acute bilirubin encephalopathy. Differently colored nodes represent different proteins; lines represent interactions between proteins; line width represents comprehensive score (0.4-1.0) of interaction between proteins. The wider the line, the higher the score. The default minimum score was selected as medium score (0.4). Red ellipse represents the immune and complement cascades; blue ellipse represents the immune and inflammation processes.

A

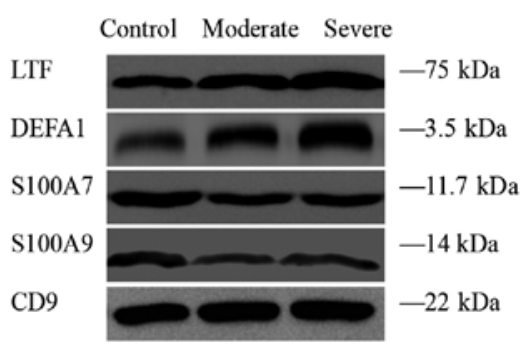

B

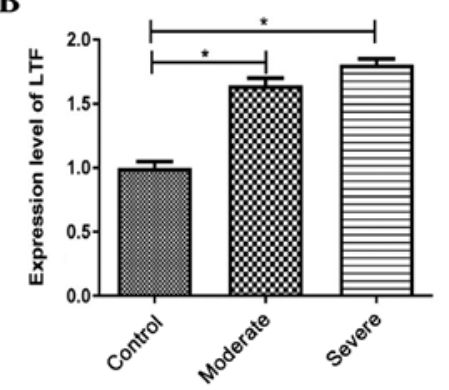

$\mathbf{E}$

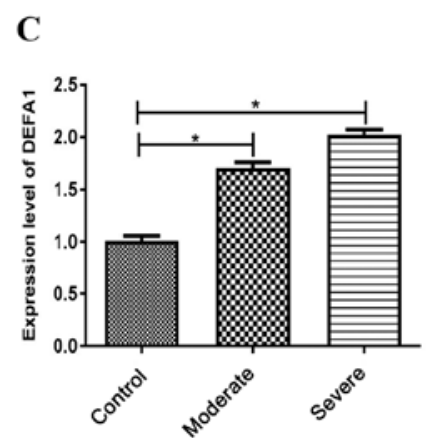

D

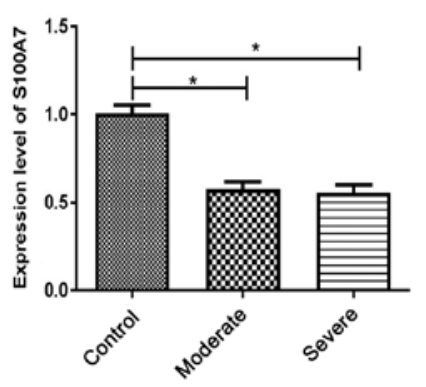

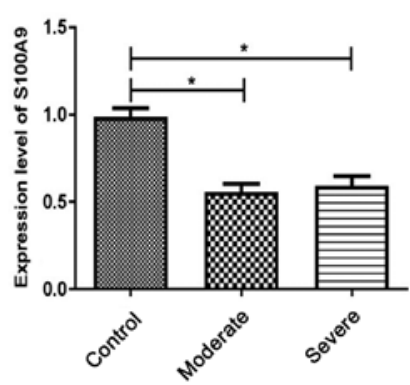

Figure 6. Verification of differentially expressed proteins using western blotting. (A) Representative western blots demonstrate the expression levels of LTF, DEFA1, S100A7 and S100A9 in the MV/E isolated from the CSF. Histogram data shows the densitometric semi-quantification (mean \pm SD) of (B) LTF, (C) DEFA1, (D) S100A7 and (E) S100A9 expression levels. Protein densitometric semi-quantification was normalized to the density of CD9 protein. CD9 is an exosome surface marker. ${ }^{*} \mathrm{P}<0.05$. LTF, lactoferrin; DEFA1, $\alpha$ defensin 1; MV/E, microvesicle/exosome.

ABE included 'Ras signaling pathway', 'PI3K-AKT signaling pathway', 'MAPK signaling pathway', 'cytokine-cytokine receptor interaction', 'Rap1 signaling pathway', 'mTOR signaling pathway' and 'NF-kB signaling pathway' (Fig. 4B).
Other enriched signaling pathways were identified, including 'HIF-1 signaling pathway', 'mTOR signaling pathway', 'NF- $\mathrm{B}$ signaling pathway', 'Neuroactive ligand-receptor interaction', and 'ECM-receptor interaction'. 
PPI of DEPs. STRING software was used to construct a potential PPI of the identified DEPs. The robust and cross-talking interactions are mapped in Fig. 5. The DEPs were discovered to be associated with the immune system and inflammation. In particular, the functions of serum amyloid A-1 protein (SAA1), amyloid- $\beta$ precursor protein (APP), complement $C 4-B$ (C4B), complement C5 (C5), DEFA1, LTF, C-reactive protein (CRP), S100A7, S100A9 and lipopolysaccharide-binding protein (LBP) were demonstrated to be associated with each other.

Verification of DEPs using western blotting. Based on the comprehensive analysis of the pathogenesis and bioinformatics of ABE, four candidate DEPs (S100A9, S100A7, LTF and DEFA1) were further verified by western blotting and an additional 12 participants were enrolled for the validation. These participants included 4 patients with moderate ABE, 4 with severe $\mathrm{ABE}$ and 4 controls. The expression levels of LTF and DEFA1 were significantly upregulated (Fig. 6A-C), while the expression levels of S100A7 and S100A9 were significantly downregulated (Fig. 6A, D and E) in both the moderate and severe patients with ABE compared with the control groups; these findings were consistent with the LC-MS/MS data.

\section{Discussion}

The incidence of clinical ABE is high, particularly in developing countries, and subclinical BE (hypobilirubin encephalopathy) is also seen in clinical practice (6-8). The pathogenesis of BE is still unclear. In the present study, iTRAQ-based quantitative proteomic technology combined with LC/MS/MS was used to identify the proteomic profile of MV/E obtained from the CSF of patients with ABE. Certain DEPs [SAA1, APP, LBP, CRP, immunoglobulin, complement components (C4B and C5), S100A9, S100A7, DEFA1 and LTF] associated with the immune-inflammatory response were identified in the extracellular vesicles, which indicated that these extracellular vesicles may serve an important role in the pathophysiology of bilirubin-induced neurological neurotoxicity by regulating and transmitting complex communication among neurocytes.

Since the discovery of circulating extracellular vesicles in 1979 (31), there has been a rapid increase in scientific research on vesicles. Previous studies have suggested that extracellular vesicles may serve a crucial role in the pathophysiology of neurologic disorders by regulating the communication among neurocytes via complex mechanisms $(32,21)$. Exosomes have been demonstrated to promote neurite growth and enhance axonal regeneration in injured neurons (33). Moreover, the cargo of extracellular vesicles has been discovered to be involved in the mechanisms underlying traumatic brain injury (32). However, to the best of our knowledge, the role of extracellular vesicles in bilirubin-induced neurological injury is not well characterized. In the present study, MV/E were isolated from the CSF of patients with $\mathrm{ABE}$ and changes in the proteomic profiles in these extracellular vesicles were identified. Certain DEPs were associated with immune-inflammation; these included SAA1, APP, LBP, CRP, immunoglobulin, complement components (C4B and C5), S100A9, S100A7, DEFA1 and LTF. In addition, GO annotation and enrichment analysis of the DEPs revealed that the majority of the DEPs were primarily associated with 'immune system process', 'biological regulation' or 'molecular transducer activity'. KEGG signaling pathway enrichment analysis also demonstrated that these DEPs were primarily enriched in immune and inflammatory signaling pathways ('PI3K-AKT signaling pathway', 'NF- $\mathrm{B}$ signaling pathway' and 'MAPK signaling pathway'). In particular, the NF-кB signaling pathway and MAPK signaling pathway are important immune-inflammatory pathways, which have been reported to be activated by UCB at an early stage of brain development (15). These findings indicated that the DEPs identified in the extracellular vesicles of patients with CSF may serve a critical role in the pathogenesis of bilirubin-induced cerebral injury.

Previous studies have demonstrated that hazardous levels of UCB may induce the acute and chronic activation of microglia and astrocytes via the upregulation of proinflammatory gene expression levels, subsequently triggering the release of inflammatory biomarkers, such as IL- $1 \beta$, TNF- $\alpha$ and IL-6 (14,34-37). Hazardous levels of UCB were discovered to induce the unfolded protein response and endoplasmic reticulum stress, which contributed to neuronal inflammation by inducing IL-8 expression levels via the regulation of the upstream NF-kB/PKR-like endoplasmic reticulum kinase axis $(18,38,39)$. These results are consistent with the findings of the present bioinformatics analysis, which revealed the enrichment of the 'NF-kappa B signaling pathway'. These bilirubin-induced immune-inflammatory signaling pathways and biomarkers have been identified previously to contribute to neuronal apoptosis, necrosis or pyroptosis (40). Altogether, these results suggested that bilirubin-induced neurological neurotoxicity may be associated with certain immune-inflammatory processes.

The present study demonstrated differential expression levels of certain proteins in the CSF of patients with $\mathrm{ABE}$ associated with immune-inflammation, including APP, LBP and CRP. In a previous study, APP protein was demonstrated to induce a predominantly proinflammatory phenotype of microglia in Alzheimer's disease (41). Moreover, LBP and CRP, which are non-specific markers of inflammation, were found to be significantly increased in the serum of patients with traumatic brain injury $(42,43)$. Although these non-specific immune-inflammatory markers have been studied in the context of traumatic brain injury and neurodegenerative diseases, to the best of our knowledge, their role in the context of UCB-induced neurological dysfunction is not well characterized. The significant increase in APP, LBP and CRP expression levels in extracellular vesicles isolated from the CSF in the present study may represent the physiological and compensatory immune-inflammatory response to UCB. However, further investigations are required to verify the association between these proteins and bilirubin-induced neurological neurotoxicity.

The preset study also demonstrated the significant upregulation of complement-associated proteins, such as $\mathrm{C} 4 \mathrm{~B}$ and C5, in patients with ABE. Previous studies have reported that both neurons and glial cells are capable of synthesizing complement receptors $(44,45)$. The complement system is hypothesized to serve an important role in brain homeostasis, neural development, central nervous system (CNS) repair, regeneration, neuroprotection, neurogenesis and the progression of pathology in neurodegenerative disorders, stroke and 
traumatic brain injury (46-48). These studies showed that the levels of complement components were upregulated. The present results are consistent with these studies. However, to the best of our knowledge, no previous studies have investigated the association between complement and bilirubin-induced brain injury. The present study demonstrated the significant upregulation of numerous immunoglobulin-like domains, such as immunoglobulin heavy constant $\gamma 4$ and immunoglobulin heavy variable 2-5 in $\mathrm{MV} / \mathrm{E}$ isolated from the CSF of patients with $\mathrm{ABE}$. Immunoglobulins are an essential component of the immune response (49). These immunoglobulin-like domains have been suggested to serve as neural cell adhesion molecules that mediate interactions among nerve cells in the brain (50). Thus, extreme hyperbilirubinemia may trigger the complement system and upregulate certain immunoglobulin-like domains. However, further investigations are required to assess whether the upregulation of complement-associated proteins and immunoglobulin-like domains observed in CSF vesicles serve an important role in $\mathrm{ABE}$.

S100A9, is a $\mathrm{Ca}^{2+}$-binding protein belonging to the $\mathrm{S} 100$ family, which is primarily derived from immunocytes (neutrophils, macrophages and myeloid-derived dendritic cells), but also expressed in astrocytes and neurons (51). S100A9 has been reported to activate multiple immune-inflammatory regulation signaling pathways, including Ras/ERK/NF- $\kappa \mathrm{B}$ and PI3K/Akt in astrocytes $(52,53)$. Moreover, the overexpression of S100A9 in neurons was identified to be involved in the infiltration of microglia and the growth of primary astrocytes in vitro via the activation of 'Ras signaling pathways' (54). Thus, these studies suggested that S100A9 may be an important immune inflammatory biomarker in the nervous system, which participates in the inflammatory process.

Although the upregulation of S100A9 may be involved in the immune-inflammatory response in numerous types of neuronal disorder, the present results demonstrated a significant downregulation of S100A9 expression levels in MV/E isolated from the CSF of patients with $\mathrm{ABE}$. These results indicated that the balance of neurological immune-inflammatory regulation functions of S100A9 may be disrupted by hyperbilirubinemia; alternatively, the downregulation of S100A9 expression levels in the $\mathrm{MV} / \mathrm{E}$ may be an intrinsic protective mechanism to trigger tissue proliferation or repair activity following the exposure to hyperbilirubinemia. S100A9 serves multiple biological roles depending on the concentration, as well as the proximal microenvironment (55). Numerous studies have demonstrated that S100A9 is involved in the modulation of cellular proliferation, differentiation and apoptosis, as well as proinflammatory and anti-inflammatory functions $(56,57)$. At high concentrations, extracellular S100A9 exhibited proinflammatory functions and growth-inhibitory activity, induced cell apoptosis, and exerted deleterious effects by stimulating leukocyte migration and recruitment, enhancing leukocyte-endothelial contact and increasing vascular permeability (58-61). However, at low levels, extracellular S100A9 was reported to exert either anti-inflammatory properties to avoid tissue damage, or tissue proliferation/repair activity at local inflammatory sites (55). Thus, the downregulated expression levels of S100A9 may be associated with its intrinsic protective mechanism to trigger tissue proliferation or repair activity following exposure to hyperbilirubinemia. However, the association between the downregulation of S100A9 and its anti-inflammatory or intrinsic protective effects in bilirubin-induced brain injury requires further investigation. Additionally, since the S100A9 protein in the present study was detected in extracellular vesicles, it may differ from studies in which the protein was detected in total CSF $(62,63)$. The S100A9 in extracellular vesicles represents the storage of extracellular S100A9 in the brain (64). Physiologically, there is sufficient storage of S100A9 in astrocytes or neurons; however, trauma, heat, stress, infection and inflammation have all been identified to trigger its upregulation and active release (55). Therefore, further investigations are required to determine whether the downregulated expression levels of S100A9 in extracellular vesicles are due to the release of S100A9 from extracellular vesicles into the CSF. Whether the downregulated expression levels of S100A9 and increased severity of bilirubin-induced brain damage are due to impaired neuronal function or gene suppression also remains to be elucidated.

S100A7 is also an important member of the S100 family, which contains the EF-hand calcium-binding protein (65). S100A7 is a proinflammatory protein expressed in immune cells and in neurons, microglia and astrocytes in the brain (66). S100A7 was also observed to be expressed in glial and meningeal cells, which supports the hypothesis that S100A7 may be associated with immune-inflammatory processes in the CNS (66). A previous study documented increased levels of S100A7 in the CSF of patients with Alzheimer's disease (67). However, the present study demonstrated a significant downregulation in the expression levels of S100A7 in the $\mathrm{MV} / \mathrm{E}$ isolated from the CSF of patients with ABE. A study by Sharma et al (68) also reported a significant decrease in the serum levels of S100A7 in patients with acute ischemic stroke. Similar to S100A9, S100A7 expression differs between tissues and organs or in different disease states; this indicates the multifaceted nature of S100A7 function (66). The downregulated expression levels of S100A7 in the present study indicated that S100A7 may participate in BIND; however, the exact mechanism of action and function of S100A7 in this disease remains unclear. Further investigations are required to confirm the results of the present study.

In addition to the downregulation of S100A9 and S100A7 expression levels, the present study also identified the upregulation of the expression levels of certain bioactive proteins, including defensins and LTF, which regulate immune-inflammatory responses, as well as antioxidant and neuroprotective processes $(69,70)$. The present study identified the significant upregulation of DEFA1 expression levels in the MV/E isolated from the CSF of patients with ABE. Defensins are antimicrobial peptides that serve multifaceted roles and exhibit immunomodulatory and anti-inflammatory properties $(71,72)$. Variable expression levels of defensins have been identified in cerebral microglia and astrocytes in both the mouse and human brain, where they have been observed to serve complex roles in immunomodulatory processes $(73,74)$. Moreover, following the injury to the CNS, microglia and astrocytes provided immune defense in a stimulus-dependent manner via the production and release of defensins (75). As ABE is a form of secondary brain injury caused by hyperbilirubinemia, the upregulated expression levels of DEFA1 indicated that DEFA1 may serve an important immunomodulatory role in the pathogenesis of 
bilirubin-induced brain injury. Additionally, as defensins are anti-inflammatory peptides (76), the upregulated expression levels of DEFA1 may have had an anti-inflammatory neuroprotective function by preventing the excessive inflammation in brain lesions. Thus, the findings of the present study suggested that DEFA1 may be important in the immunomodulatory and anti-inflammatory processes of bilirubin-induced neurological neurotoxicity; however, further investigations are required to elucidate the underlying mechanism.

The present study also demonstrated that the expression levels of LTF were significantly upregulated in the MV/E of patients with ABE. LTF is an iron-binding glycoprotein that belongs to the transferrin family and serves numerous beneficial biological functions, such as immunomodulatory, antioxidant and neuroprotective effects (77). Previously, LTF was observed to modulate the migration, maturation and function of immune cells $(78,79)$. In addition, the expression levels of LTF in biological fluids were significantly upregulated in patients with inflammatory diseases (80). Moreover, in addition to the immune-inflammatory mechanisms, oxidative stress is also hypothesized to be an important pathogenetic mechanism of bilirubin encephalopathy (81). The upregulated expression levels of LTF indicated that it may be involved in maintaining hemostasis between oxidation and anti-oxidation. Previous studies have shown that $\mathrm{ABE}$ is partly caused by oxidative stress and brain cell damage induced by high bilirubin levels $(11,81)$. LTF has been demonstrated to possess antioxidant properties (77). Therefore, the upregulated expression levels of LTF in the present study may be involved in maintaining homeostasis between oxidation and anti-oxidation.

LTF has been previously demonstrated to exhibit antioxidant properties, in addition to decreasing ROS generation and removing ROS from the brain; LTF was also reported to help maintain the levels of ascorbate and glutathione, which are important endogenous antioxidants $(70,82)$. These previous findings indicated that the upregulated expression levels of LTF may improve the antioxidant capacity of the brain. Furthermore, LTF has been demonstrated to exert neuroprotective effects on the immature brain in rodent models of intrauterine growth restriction and cerebral hypoxia/ischemia $(83,84)$. A number of studies have also revealed that upregulated expression levels of LTF served as an important neuroprotective factor, potentially due to its capacity to stimulate cell cycle progression and induce erythropoietin synthesis $(77,85)$. Overall, the upregulated expression levels of LTF in ABE indicated that it may either modulate immune-inflammatory processes or exert antioxidant or neuroprotective effects in the pathological process of BIND. However, the mechanism linking LTF with BIND still needs to be evaluated.

In conclusion, the present study determined the proteomic profile of extracellular vesicles (MV/E) isolated from the CSF of patients with ABE. The findings of the present study provided an improved understanding of the pathophysiology of BIND. Certain proteins and signaling pathways involved in the $\mathrm{MV} / \mathrm{E}$ were primarily associated with the immune-inflammatory response. This indicated that extracellular vesicles may serve an important role in the development of bilirubin-induced neurological neurotoxicity via immune-inflammatory proteins and signaling pathways. Moreover, extracellular vesicles in the
CSF are derived from neurocytes; thus, their cargo (S100A9, S100A7, DEFA1 and LTF) represents the microenvironment of the brain and offers information about the pathophysiology of cerebral injury for patients with ABE (86). Altered DEP levels in extracellular vesicles of CSF results in changes to the microenvironment of the brain and the adaptation process of nerve cells due to hyperbilirubinemia. The results therefore suggested that extracellular vesicles and the identified proteins may serve as biomarkers and provide a critical advantage over traditional biomarkers in the early diagnosis of ABE. Currently, the diagnosis of ABE primarily depends on clinical manifestations and cranial MRI scans. Extracellular vesicles and proteins may serve as objective biomarkers. Furthermore, due to the lack of specific drug therapeutic options for ABE, extracellular vesicles may present a novel therapeutic target; the immune-inflammatory targets involved in extracellular vesicles may be engineered to regulate intercellular communication and improve the outcomes for patients with ABE, which could provide novel therapeutic perspectives. Thus, further investigations are required to determine the usefulness of MV/E as early diagnostic biomarkers and novel therapeutic targets for ABE.

\section{Acknowledgements}

Not applicable.

\section{Funding}

The present work was supported by the Hunan Provincial Science and Technology Department, China (grant no. 2019JJ80059) and the Health and Family Planning Commission of Hunan Province, China (grant no. B20180259).

\section{Availability of data and materials}

The datasets used and/or analyzed during the current study are available from the corresponding author on reasonable request.

\section{Authors' contributions}

BW and NT designed the study and wrote the manuscript. $\mathrm{SH}, \mathrm{ZW}$ and BW wrote the manuscript. NT, SH, ZW and $\mathrm{ZH}$ performed the proteome experiments and western blotting analysis. NT, ZW and BW revised the manuscript. All authors read and approved the final manuscript.

\section{Ethics approval and consent to participate}

The study protocol was approved by the Ethics Committee of Affiliated First People's Hospital of Chenzhou, Southern Medical University (approval no. 2019049; Chenzhou, China). Written informed consent was obtained from parents/caregivers of all subjects prior to the start of the study. All experimental procedures were performed in accordance with the Declaration of Helsinki.

\section{Patient consent for publication}

Not applicable. 


\section{Competing interests}

The authors declare that they have no competing interests.

\section{References}

1. Bhutani VK, Stark AR, Lazzeroni LC, Poland R, Gourley GR, Kazmierczak S, Meloy L, Burgos AE, Hall JY and Stevenson DK Predischarge screening for severe neonatal hyperbilirubinemia identifies infants who need phototherapy. J Pediatr 162: 477-482.e1, 2013.

2. Bech LF, Donneborg ML, Lund AM and Ebbesen F: Extreme neonatal hyperbilirubinemia, acute bilirubin encephalopathy, and kernicterus spectrum disorder in children with galactosemia. Pediatr Res 84: 228-232, 2018.

3. Bahr TM, Christensen RD, Agarwal AM, George TI and Bhutani VK: The neonatal acute bilirubin encephalopathy registry (NABER): Background, aims, and protocol. Neonatology 115: 242-246, 2019.

4. Christensen RD, Agarwal AM, George TI, Bhutani VK and Yaish HM: Acute neonatal bilirubin encephalopathy in the state of utah 2009-2018. Blood Cells Mol Dis 72: 10-13, 2018.

5. McGillivray A and Evans N: Severe neonatal jaundice: Is it a rare event in Australia? J Paediatr Child Health 48: 801-807, 2012.

6. Olusanya BO, Kaplan M and Hansen TWR: Neonatal hyperbilirubinaemia: A global perspective. Lancet Child Adolesc Health 2: 610-620, 2018.

7. Diala UM, Wennberg RP, Abdulkadir I, Farouk ZL, Zabetta CDC Omoyibo E, Emokpae A, Aravkin A, Toma B, Oguche S, et al; On behalf of the Stop Kernicterus In Nigeria (SKIN) study group: Patterns of acute bilirubin encephalopathy in Nigeria: A multicenter pre-intervention study. J Perinatol 38: 873-880, 2018.

8. Morioka I, Nakamura H,Koda T, Yokota T, Okada H, Katayama Y, Kunikata T, Kondo M, Nakamura M, Hosono S, et al: Current incidence of clinical kernicterus in preterm infants in Japan. Pediatr Int 57: 494-497, 2015

9. Radmacher PG, Groves FD, Owa JA, Ofovwe GE, Amuabunos EA, Olusanya BO and Slusher TM: A modified Bilirubin-induced neurologic dysfunction (BIND-M) algorithm is useful in evaluating severity of jaundice in a resource-limited setting. BMC Pediatr 15: 28, 2015.

10. Morioka I, Iwatani S, Koda T, Iijima K and Nakamura H: Disorders of bilirubin binding to albumin and bilirubin-induced neurologic dysfunction. Semin Fetal Neonatal Med 20: 31-36, 2015.

11. Watchko JF: Kernicterus and the molecular mechanisms of bilirubin-induced CNS injury in newborns. Neuromolecular Med 8: 513-529, 2006.

12. Deganuto M, Cesaratto L, Bellarosa C, Calligaris R, Vilotti S, Renzone G, Foti R, Scaloni A, Gustincich S, Quadrifoglio F, et al: A proteomic approach to the bilirubin-induced toxicity in neuronal cells reveals a protective function of DJ-1 protein Proteomics 10: 1645-1657, 2010.

13. Brites D: The evolving landscape of neurotoxicity by unconjugated bilirubin: Role of glial cells and inflammation. Front Pharmacol 3: 88, 2012.

14. Watchko JF and Tiribelli C: Bilirubin-induced neurologic damage - mechanisms and management approaches. N Engl J Med 369: 2021-2030, 2013.

15. Silva SL, Vaz AR, Barateiro A, Falcão AS, Fernandes A, Brito MA, Silva RF and Brites D: Features of bilirubin-induced reactive microglia: From phagocytosis to inflammation. Neurobiol Dis 40: 663-675, 2010.

16. Brites D: Bilirubin injury to neurons and glial cells: New players, novel targets, and newer insights. Semin Perinatol 35: 114-120, 2011.

17. Daood M, Tsai C, Ahdab-Barmada $M$ and Watchko JF: ABC transporter (P-gp/ABCB1, MRP1/ABCC1, BCRP/ABCG2) expression in the developing human CNS. Neuropediatrics 39 . 211-218, 2008

18. Qaisiya M, Brischetto C, Jašprová J, Vitek L, Tiribelli C and Bellarosa C: Bilirubin-induced ER stress contributes to the inflammatory response and apoptosis in neuronal cells. Arch Toxicol 91: 1847-1858, 2017.

19. Chivet M, Javalet C, Laulagnier K, Blot B, Hemming FJ and Sadoul R: Exosomes secreted by cortical neurons upon glutamatergic synapse activation specifically interact with neurons. J Extracell Vesicles 3: 24722, 2014.
20. Izadpanah M, Seddigh A, Ebrahimi Barough S, Fazeli SAS and Ai J: Potential of extracellular vesicles in neurodegenerative diseases: Diagnostic and therapeutic indications. J Mol Neurosci 66: 172-179, 2018

21. Paolicelli RC, Bergamini G and Rajendran L: Cell-to-cell communication by extracellular vesicles: Focus on microglia. Neuroscience 405: 148-157, 2019.

22. Xiong XG, Liang Q, Zhang C, Wang Y, Huang W, Peng W, Wang $\mathrm{Z}$ and $\mathrm{Xia} \mathrm{ZA}$ : Serum proteome alterations in patients with cognitive impairment after traumatic brain injury revealed by itraq-based quantitative proteomics. BioMed Res Int 2017: 8572509,2017

23. Núñez Galindo A, Macron C, Cominetti O and Dayon L: Analyzing cerebrospinal fluid proteomes to characterize central nervous system disorders: A highly automated mass spectrometry-based pipeline for biomarker discovery. Methods Mol Biol 1959: 89-112, 2019.

24. Adav SS, Park JE and Sze SK: Quantitative profiling brain proteomes revealed mitochondrial dysfunction in Alzheimer's disease. Mol Brain 12: 8, 2019.

25. Bortolussi G, Codarin E, Antoniali G, Vascotto C, Vodret S, Arena S, Cesaratto L, Scaloni A, Tell G and Muro AF: Impairment of enzymatic antioxidant defenses is associated with bilirubin-induced neuronal cell death in the cerebellum of Ugt1 KO mice. Cell Death Dis 6: e1739, 2015.

26. Chiasserini D, van Weering JRT, Piersma SR, Pham TV, Malekzadeh A, Teunissen CE, de Wit H and Jiménez CR: Proteomic analysis of cerebrospinal fluid extracellular vesicles: A comprehensive dataset. J Proteomics 106: 191-204, 2014.

27. World Medical Association: World Medical Association Declaration of Helsinki: Ethical Principles for Medical Research Involving Human Subjects. JAMA 310: 2191-2194, 2013.

28. Bhutani VK and Johnson-Hamerman L: The clinical syndrome of bilirubin-induced neurologic dysfunction. Semin Fetal Neonatal Med 20: 6-13, 2015

29. Gardiner C, Ferreira YJ, Dragovic RA, Redman CW and Sargent IL: Extracellular vesicle sizing and enumeration by nanoparticle tracking analysis. J Extracell Vesicles 2: 2, 2013.

30. Shao H, Im H, Castro CM, Breakefield X, Weissleder R and Lee H: New technologies for analysis of extracellular vesicles. Chemical reviews 118:1917-1950,2018.

31. Taylor DD and Doellgast GJ: Quantitation of peroxidase-antibody binding to membrane fragments using column chromatography. Anal Biochem 98: 53-59, 1979.

32. Osier N, Motamedi V, Edwards K, Puccio A, Diaz-Arrastia R, Kenney K and Gill J: Exosomes in acquired neurological disorders: New insights into pathophysiology and treatment. Mol Neurobiol 55: 9280-9293, 2018

33. Tang BL: Promoting axonal regeneration through exosomes: An update of recent findings on exosomal PTEN and mTOR modifiers. Brain Res Bull 143: 123-131, 2018.

34. Fernandes A, Barateiro A, Falcão AS, Silva SL, Vaz AR, Brito MA, Silva RF and Brites D: Astrocyte reactivity to unconjugated bilirubin requires TNF- $\alpha$ and IL- $1 \beta$ receptor signaling pathways. Glia 59: 14-25, 2011

35. Li M, Song S, Li S, Feng J and Hua Z: The blockade of nf-kappab activation by a specific inhibitory peptide has a strong neuroprotective role in a sprague-dawley rat kernicterus model. J Biol Chem 290: 30042-30052, 2015.

36. Watchko JF: Bilirubin-induced neurotoxicity in the preterm neonate. Clin Perinatol 43: 297-311, 2016.

37. Watchko JF and Maisels MJ: The enigma of low bilirubin kernicterus in premature infants: Why does it still occur, and is it preventable? Semin Perinatol 38: 397-406, 2014

38. Vodret S, Bortolussi G, Jašprová J, Vitek L and Muro AF: Inflammatory signature of cerebellar neurodegeneration during neonatal hyperbilirubinemia in $\mathrm{Ugt}^{-/-}$mouse model. J Neuroinflammation 14: 64, 2017.

39. Kitamura M: Control of NF- $\mathrm{kB}$ and inflammation by the unfolded protein response. Int Rev Immunol 30: 4-15, 2011.

40. Feng J, Li M, Wei Q, Li S, Song S and Hua Z: Unconjugated bilirubin induces pyroptosis in cultured rat cortical astrocytes. J Neuroinflammation 15: 23, 2018.

41. Zhu M, Wang X, Schultzberg M and Hjorth E: Differential regulation of resolution in inflammation induced by amyloid- $\beta 42$ and lipopolysaccharides in human microglia. J Alzheimers Dis 43: $1237-1250,2015$

42. Davies MG and Hagen PO: Systemic inflammatory response syndrome. Br J Surg 84: 920-935, 1997. 
43. Anada RP, Wong KT, Jayapalan JJ, Hashim OH and Ganesan D: Panel of serum protein biomarkers to grade the severity of traumatic brain injury. Electrophoresis 39: 2308-2315, 2018.

44. Gasque P, Fontaine M and Morgan BP: Complement expression in human brain. Biosynthesis of terminal pathway components and regulators in human glial cells and cell lines. Immunol 154: 4726-4733, 1995.

45. Nataf S, Levison SW and Barnum SR: Expression of the anaphylatoxin C5a receptor in the oligodendrocyte lineage. Brain Res 894: 321-326, 2001.

46. Hammad A, Westacott L and Zaben M: The role of the complement system in traumatic brain injury: A review. J Neuroinflammation 15: 24, 2018.

47. Brennan FH, Anderson AJ, Taylor SM, Woodruff TM and Ruitenberg MJ: Complement activation in the injured central nervous system: Another dual-edged sword? J Neuroinflammation 9: 137, 2012.

48. Bellander BM, Olafsson IH, Ghatan PH, Bro Skejo HP Hansson LO, Wanecek M and Svensson MA: Secondary insults following traumatic brain injury enhance complement activation in the human brain and release of the tissue damage marker S100B. Acta Neurochir (Wien) 153: 90-100, 2011.

49. Stoll BJ, Lee FK, Hale E, Schwartz D, Holmes R, Ashby R, Czerkinsky $\mathrm{C}$ and Nahmias AJ: Immunoglobulin secretion by the normal and the infected newborn infant. J Pediatr 122: 780-786, 1993

50. Zinn K and Özkan E: Neural immunoglobulin superfamily interaction networks. Curr Opin Neurobiol 45: 99-105, 2017.

51. Denstaedt SJ, Spencer-Segal JL, Newstead MW, Laborc K, Zhao AP, Hjelmaas A, Zeng X, Akil H, Standiford TJ and Singer BH: S100a8/a9 drives neuroinflammatory priming and protects against anxiety-like behavior after sepsis. J Immunol 200: 3188-3200, 2018.

52. Hermani A, De Servi B, Medunjanin S, Tessier PA and Mayer D: S100A8 and S100A9 activate MAP kinase and NF-kappaB signaling pathways and trigger translocation of RAGE in human prostate cancer cells. Exp Cell Res 312: 184-197, 2006.

53. Ghavami S, Rashedi I, Dattilo BM, Eshraghi M, Chazin WJ, Hashemi M, Wesselborg S, Kerkhoff C and Los M: S100A8/A9 at low concentration promotes tumor cell growth via RAGE ligation and MAP kinase-dependent pathway. J Leukoc Biol 83: 1484-1492, 2008.

54. Ryu MJ,Liu Y,Zhong X, Du J, Peterson N, Kong G, Li H, Wang J, Salamat S, Chang Q, et al: Oncogenic Kras expression in postmitotic neurons leads to S100A8-S100A9 protein overexpression and gliosis. J Biol Chem 287: 22948-22958, 2012.

55. Wang S, Song R, Wang Z, Jing Z, Wang S and Ma J: S100A8/A9 in Inflammation. Front Immunol 9: 1298, 2018.

56. Low D, Subramaniam R, Lin L, Aomatsu T, Mizoguchi A, Ng A, DeGruttola AK, Lee CG, Elias JA, Andoh A, et al: Chitinase 3-like 1 induces survival and proliferation of intestinal epithelial cells during chronic inflammation and colitis-associated cancer by regulating S100A9. Oncotarget 6: 36535-36550, 2015.

57. Donato R, Cannon B, Sorci G, Riuzzi F, Hsu K, Weber D and Geczy C: Functions of s100 proteins. Curr Mol Med 13: 24-57, 2013.

58. Ryckman C, Vandal K, Rouleau P, Talbot M and Tessier PA: Proinflammatory activities of s100: Proteins s100a8, s100a9, and s100a8/a9 induce neutrophil chemotaxis and adhesion. J Immunol 170: 3233-3242, 2003.

59. Pruenster M, Kurz AR, Chung KJ, Cao-Ehlker X, Bieber S, Nussbaum CF, Bierschenk S, Eggersmann TK, Rohwedder I, Heinig K, et al: Extracellular MRP8/14 is a regulator of $\beta 2$ integrin-dependent neutrophil slow rolling and adhesion. Nat Commun 6: 6915, 2015.

60. Nishikawa Y, Kajiura Y, Lew JH, Kido JI, Nagata T and Naruishi K: Calprotectin induces il- 6 and mcp-1 production via toll-like receptor 4 signaling in human gingival fibroblasts. J Cell Physiol 232: 1862-1871, 2017.

61. Ma L, Sun P, Zhang JC, Zhang Q and Yao SL: Proinflammatory effects of S100A8/A9 via TLR4 and RAGE signaling pathways in BV-2 microglial cells. Int J Mol Med 40: 31-38, 2017.

62. Horvath I, Jia X, Johansson P, Wang C, Moskalenko R, Steinau A, Forsgren L, Wågberg $\mathrm{T}$, Svensson $\mathrm{J}$, Zetterberg $\mathrm{H}$, et al: Pro-inflammatory s100a9 protein as a robust biomarker differentiating early stages of cognitive impairment in alzheimer's disease. ACS Chem Neurosci 7: 34-39, 2016.

63. Wache C, Klein M, Ostergaard C, Angele B, Häcker H, Pfister HW, Pruenster M, Sperandio M, Leanderson T, Roth J, et al: Myeloid-related protein 14 promotes inflammation and injury in meningitis. J Infect Dis 212: 247-257, 2015.
64. Meldolesi J: Exosomes and ectosomes in intercellular communication. Curr Biol 28: R435-R444, 2018.

65. Fritz G, Botelho HM, Morozova-Roche LA and Gomes CM: Natural and amyloid self-assembly of S100 proteins: Structural basis of functional diversity. FEBS J 277: 4578-4590, 2010.

66. Jansen S, Podschun R, Leib SL, Grötzinger J, Oestern S, Michalek M, Pufe T and Brandenburg LO: Expression and function of psoriasin (S100A7) and koebnerisin (S100A15) in the brain. Infect Immun 81: 1788-1797, 2013.

67. Qin W, Ho L, Wang J, Peskind E and Pasinetti GM: S100A7, a novel Alzheimer's disease biomarker with non-amyloidogenic alpha-secretase activity acts via selective promotion of ADAM-10. PLoS One 4: e4183, 2009.

68. Sharma R, Gowda H, Chavan S, Advani J, Kelkar D, Kumar GS, Bhattacharjee M, Chaerkady R, Prasad TS, Pandey A, et al: Proteomic signature of endothelial dysfunction identified in the serum of acute ischemic stroke patients by the itraq-based lc-ms approach. J Proteome Res 14: 2466-2479, 2015.

69. Kim C and Kaufmann SH: Defensin: A multifunctional molecule lives up to its versatile name. Trends Microbiol 14: 428-431, 2006.

70. Park YG, Jeong JK, Lee JH, Lee YJ, Seol JW, Kim SJ, Hur TY, Jung YH, Kang SJ and Park SY: Lactoferrin protects against prion protein-induced cell death in neuronal cells by preventing mitochondrial dysfunction. Int J Mol Med 31: 325-330,2013.

71. Semple F and Dorin JR: $\beta$-Defensins: Multifunctional modulators of infection, inflammation and more? J Innate Immun 4: 337-348, 2012.

72. Tollner TL, Bevins CL and Cherr GN: Multifunctional glycoprotein DEFB126 - a curious story of defensin-clad spermatozoa. Nat Rev Urol 9: 365-375, 2012.

73. Kazakos EI, Kountouras J, Polyzos SA and Deretzi G: Novel aspects of defensins' involvement in virus-induced autoimmunity in the central nervous system. Med Hypotheses 102: 33-36, 2017.

74. Williams WM, Torres S, Siedlak SL, Castellani RJ, Perry G, Smith MA and Zhu X: Antimicrobial peptide $\beta$-defensin- 1 expression is upregulated in Alzheimer's brain. J Neuroinflammation 10: 127, 2013

75. Rocha-Ferreira E and Hristova M: Antimicrobial peptides and complement in neonatal hypoxia-ischemia induced brain damage. Front Immunol 6: 56, 2015.

76. Miles K, Clarke DJ, Lu W, Sibinska Z, Beaumont PE, Davidson DJ, Barr TA, Campopiano DJ and Gray M: Dying and necrotic neutrophils are anti-inflammatory secondary to the release of alpha-defensins. J Immunol 183: 2122-2132, 2009.

77. Zakharova ET, Sokolov AV, Pavlichenko NN, Kostevich VA, Abdurasulova IN, Chechushkov AV, Voynova IV, Elizarova AY, Kolmakov NN, Bass MG, et al: Erythropoietin and Nrf2: Key factors in the neuroprotection provided by apo-lactoferrin. Biometals 31: 425-443, 2018.

78. Legrand D, Elass E, Carpentier M and Mazurier J: Lactoferrin: A modulator of immune and inflammatory responses. Cell Mol Life Sci 62: 2549-2559, 2005.

79. Legrand D: Lactoferrin, a key molecule in immune and inflammatory processes. Biochem Cell Biol 90: 252-268, 2012.

80. Bennett RM and Kokocinski T: Lactoferrin content of peripheral blood cells. Br J Haematol 39: 509-521, 1978.

81. Qaisiya M, Coda Zabetta CD, Bellarosa C and Tiribelli C: Bilirubin mediated oxidative stress involves antioxidant response activation via Nrf2 pathway. Cell Signal 26: 512-520, 2014.

82. Ginet V, van de Looij Y, Petrenko V, Toulotte A, Kiss J, Hüppi PS and Sizonenko SV: Lactoferrin during lactation reduces lipopolysaccharide-induced brain injury. Biofactors 42: 323-336, 2016.

83. van de Looij Y, Ginet V, Chatagner A, Toulotte A, Somm E, Hüppi PS and Sizonenko SV: Lactoferrin during lactation protects the immature hypoxic-ischemic rat brain. Ann Clin Transl Neurol 1: 955-967, 2014.

84. Somm E, Larvaron P, van de Looij Y, Toulotte A, Chatagner A Faure M, Métairon S, Mansourian R, Raymond F, Gruetter R, et al: Protective effects of maternal nutritional supplementation with lactoferrin on growth and brain metabolism. Pediatr Res 75: 51-61, 2014.

85. Lee SH, Pyo CW, Hahm DH, Kim J and Choi SY: Iron-saturated lactoferrin stimulates cell cycle progression through PI3K/Akt pathway. Mol Cells 28: 37-42, 2009.

86. Thompson AG, Gray E, Heman-Ackah SM, Mäger I, Talbot K, Andaloussi SE, Wood MJ and Turner MR: Extracellular vesicles in neurodegenerative disease - pathogenesis to biomarkers. Nat Rev Neurol 12: 346-357, 2016.

This work is licensed under a Creative Commons Attribution-NonCommercial-NoDerivatives 4.0 International (CC BY-NC-ND 4.0) License. 